\title{
The bisphosphonate zoledronic acid inhibits the growth of HCT-116 colon carcinoma cells and induces tumor cell apoptosis
}

\author{
Lilian Sewing · Florian Steinberg · Harald Schmidt • \\ Rüdiger Göke
}

Published online: 25 April 2008

(C) Springer Science+Business Media, LLC 2008

\begin{abstract}
Besides its preventive action on bone resorption the third generation bisphosphonate zoledronic acid (ZOL) has been shown to display potent inhibitory action on the formation of bone metastases of various human cancers. Recent research also indicates an antitumoral effect on primary tumors and visceral metastases. Here we investigate for the first time the effect of $\mathrm{ZOL}$ on the human colon carcinoma cell line HCT-116. ZOL strongly inhibited the proliferation and soft agar colony formation of HCT-116 cells and caused a G1 cell cycle arrest in a population of ZOL treated cells. This cell cycle arrest was accompanied by an induction of apoptosis via a caspase dependent mechanism. Activation of Caspases 3, 7, 8 and 9, cleavage of PARP as well as the release of cytochrome C into the cytosol were detected in HCT-116 cells treated with low micromolar concentrations of ZOL. The induction of the mitochondrial pathway of apoptosis was accompanied by a translocation of Bax into the mitochondria, Bid activation and a decrease of overall $\mathrm{Bcl}-2$ expression. We also detected a cytosolic increase of apoptosis inducing factor (AIF), a trigger of caspase-independent apoptosis. Taken together, our data indicate a potent antitumoral and
\end{abstract}

Lilian Sewing and Florian Steinberg contributed equally to this work.

L. Sewing · H. Schmidt · R. Göke

Clinical Research Unit for Gastrointestinal Endocrinology,

University of Marburg, 35033 Marburg, Germany

F. Steinberg $(\bowtie)$

DKF Rheumatology, University of Bern, Murtenstr. 35,

3010 Bern, Switzerland

e-mail: steinberg@dkf.unibe.ch apoptosis inducing effect of ZOL on HCT-116 colon carcinoma cells.

Keywords Zoledronic acid · Apoptosis ·

Colon carcinoma $\cdot$ HCT-116

\section{Introduction}

The use of bisphosphonates for the treatment of degenerative bone diseases such as osteoporosis is well established and generally well tolerated. Due to their inhibitory action on bone resorbing osteoclasts bisphophonates prevent an excessive breakdown of bone tissue [1]. Besides its bone sparing properties, Zoledronic acid (ZOL), a third generation bisphosphonate, has been shown to exert powerful antitumoral properties in a variety of human cancers [2]. In this context ZOL is the current clinical standard for the prevention of bone metastases of human cancers. ZOL acts as an inhibitor of farnesyldiphosphate synthase [3], blocking the biosynthesis of precursors needed for the prenylation of small gtp-binding proteins, and thus not only reduces the activity of osteoclasts but also prevents or slows the progression of certain tumor cells into healthy bone tissue [4-6]. Besides its well established effect on the formation of bone metastases, there is promising evidence of a broader antitumoral activity [7]. Treatment of prostate, mammary, lung, kidney and skin cancer cell lines with ZOL resulted in a slowing of tumor cell proliferation, cell cycle arrest and induction of apoptosis [8]. Furthermore ZOL reduced the invasive behaviour of breast and prostate cancer cells which is likely due to alterations in the organization of the cytoskeleton and a reduced activity of matrix proteinases [9]. Treatment with ZOL reduces the formation of bone metastases of various tumor entities and 
significantly reduces bone related complications [10]. These findings led to the FDA approval of ZOL in combination with established antineoplastic drugs for the treatment of bone metastases of solid cancers [11]. Besides the established effect on bone metastases, there is promising evidence from animal models for the efficacy of ZOL in the treatment of primary tumors and visceral metastases. In a murine mammary tumor xenograft model $\mathrm{ZOL}$ reduced the formation of liver and lung metastases [12], while Minodronat slowed primary tumor growth and prolonged survival of mice transplanted with melanoma cells [13]. Similar results were obtained in murine models of cervical carcinoma, where ZOL reduced angiogenesis and induced apoptosis of neoplastic epithelial cells [14].

Colon carcinoma is the second most common cancer in humans with surgical removement of the primary tumor usually being the best treatment option [15]. Since any remaining tumor tissue or metastases often resist conventional chemotherapy it is necessary to develop alternative treatment options. Here we investigate for the first time the effects of the third generation bisphosphonate ZOL on a human colon carcinoma cell line, focusing on its effect on proliferation, cell cycle and apoptosis.

\section{Materials and methods}

ZOL was obtained from Sigma (Taufkirchen, Germany), dissolved in PBS and stored as a $5 \mathrm{mM}$ stock solution at $-20^{\circ} \mathrm{C}$.

\section{Cell culture}

Wildtype, p53 positive HCT-116 cells were obtained from the ATCC and kept in a standard incubator with a 5\% CO2 atmosphere and cultured in McCoy's 5A medium with media containing $10 \%$ fetal calf serum and $40 \mu \mathrm{g} / \mathrm{ml}$ gentamicin. Cells were splitted 1:10 every 5 days.

\section{MTT assay}

20.000 cells/well were seeded into twelve well plates and left there to adhere over night. The cells were then incubated for 5 days in the absence and presence of 1 to $50 \mu \mathrm{M}$ ZOL. Then $100 \mu \mathrm{l}$ methylthiazoletetrazolium $(5 \mathrm{mg} / \mathrm{ml}$ in PBS) were added and incubation continued for $2 \mathrm{~h}$. After removal of the medium cells were treated with $200 \mu \mathrm{l}$ DMSO for $15 \mathrm{~min}$. The absorbance of supernatants was determined at $550 \mathrm{~nm}$ in a multi well plate reader. The percentage of viable cells in relation to the untreated control group was calculated using the formula: (extinction of treated sample $\times 100) /($ extinction of control sample).
Soft agar assay

To study anchorage independent growth of HCT-116 cells treated with ZOL, a colony forming assay in a soft agar matrix was performed. 20,000 cells in $0.35 \%$ agar (Bacto Agar; Becton Dickinson, Franklin Lakes, NJ) were layered on top of $1 \mathrm{ml}$ of a solidified $0.6 \%$ agar layer in a $35 \mathrm{~mm}$ dish. Into the growth media with $10 \%$ FCS either $12.5 \mu \mathrm{M}$ or $25 \mu \mathrm{M}$ of ZOL were added in both layers. After 14 days of growth colonies above a chosen size on a counting grid in the microscope were counted as colonies. The number of colonies in 10 randomly chosen fields of vision was counted and compared between ZOL treated and control wells without $\mathrm{ZOL}$ in the medium. In order to take pictures of the colonies 60,000 instead of 20,000 cells were subjected to the same assay and pictures were taken using a $5 \times$ objective of a Zeiss Axiovert 10 microscope.

\section{Western blotting}

Total proteins were extracted from adherent and detached cells and protein concentration was determined using a protein assay from Bio-Rad according to the manufacturer's protocol. Proteins $(15 \mu \mathrm{g})$ were resolved by SDS/ PAGE (10\% for all proteins except cytochrome c, where a $15 \%$ gel was used) and electrotransferred onto nitrocellulose membranes (poresize $0.2 \mu \mathrm{m}$ ). Immunodetection was carried out using antibodies directed against caspase 3 (9662), caspase 7 (9492), caspase 8 (9746), caspase 9 (9502) (all from Cell Signaling Technologies, Beverly, MA, USA), Bax (N-20), AIF (D-20), Bid (C-20), Bcl-2 (C2) and $\mathrm{Bcl} / \mathrm{xl}$ (L-19) (all from Santa Cruz, Charlottesville, VA, USA), in $50 \mathrm{mM}$ Tris-HCl, $\mathrm{pH} 7.4,150 \mathrm{mM} \mathrm{NaCl}$, $0.1 \%$ Tween $20,5 \%$ non-fat dry milk, followed by HRPconjugated secondary antibodies. Detection was performed using an ECL kit (Amersham Bioscience). Cytosolic protein extracts were prepared by lysing the cells with a hypoosmotic buffer containing $20 \mathrm{mM}$ Hepes $\mathrm{pH} 7.5$, $10 \mathrm{mM}$ KCL, $1 \mathrm{mM}$ EDTA, $1 \mathrm{mM}$ DTT, $0.5 \mathrm{mM}$ Proteasearrest Inhibitor cocktail followed by ultracentrifugation at $100,000 \mathrm{~g}$ for $1 \mathrm{~h}$.

Flow cytometric cell cycle and apoptosis analysis

HCT-116 cells were incubated with 0 to $50 \mu \mathrm{M}$ ZOL for $72 \mathrm{~h}$. For the cell cycle analysis only adherent cells were harvested and fixed in ice-cold $70 \%$ (v/v) ethanol for $24 \mathrm{~h}$ at $4^{\circ} \mathrm{C}$. For the apoptosis assay adherent as well as detached cells from the culture supernatant were harvested and subjected to the same fixation method. After centrifugation the cell pellet was resuspended in PBS, $\mathrm{pH}$ 7.4, containing $1 \mu \mathrm{g} / \mathrm{ml}$ DNase-free RNase, $50 \mu \mathrm{g} / \mathrm{ml}$ propidium iodide and $0.1 \%$ glucose. Cells were incubated at room temperature in 
the dark for $4 \mathrm{~h}$, and DNA content was determined by flow cytometry using a FACScan flow cytometer (BecktonDickinson, San Jose, CA, USA). Histograms were analyzed using the Cell Quest software (Becton-Dickinson) and the ModFit 2.0 software (Verity Software House, Topsham, Me. USA). Respective to their phase-specific DNA-content cells were divided into $\mathrm{G} 1, \mathrm{~S}$ or $\mathrm{G} 2 / \mathrm{M}$ phase or counted as apoptotic cells.

\section{Statistical analysis}

Results of the soft agar assay and the flow cytometry experiments were subjected to students t-test analysis to confirm statistical significance of the data. $P$ values of less than 0.05 were considered as statistically significant.

\section{Results}

In order to test the cytotoxic potential of ZOL on HCT-116 colon carcinoma cells, cells were incubated with and without a range of $\mathrm{ZOL}$ concentrations for $5 \mathrm{~d}$ followed by an MTT test to determine the cell number in each group. Treatment of HCT-116 cells with ZOL $(0-50 \mu \mathrm{M})$ reduced cell growth dose dependently, with $50 \mu \mathrm{M}$ ZOL resulting in a more than $90 \%$ decrease in the number of viable cells after 5 days as compared to untreated control groups (Fig. 1). We next determined the effect of ZOL on the cell cycle distribution of HCT 116 cells. We therefore subjected the adherent ZOL treated cells to cell cycle analysis by PIstaining and flow cytometry as described in material and methods. The analysis revealed that ZOL induced an increase of cells in the G1 Phase of the cell cycle from $79 \%$ to $89 \%(P<0.02)$, indicating a $\mathrm{G} 1$ phase cell cycle arrest in a population of cells (Fig. 2). In agreement with this we observed a decrease of cells in the S Phase from $16 \%$ to $9 \%$ $(P<0.03)$ as well as a small decrease of $\mathrm{G} 2$ Phase cells from $5 \%$ to $2 \%(P<0.04)$. Because of the pronounced cytotoxic effect of $50 \mu \mathrm{M}$ ZOL on cells growing on a plastic surface we next tested if an intermediate

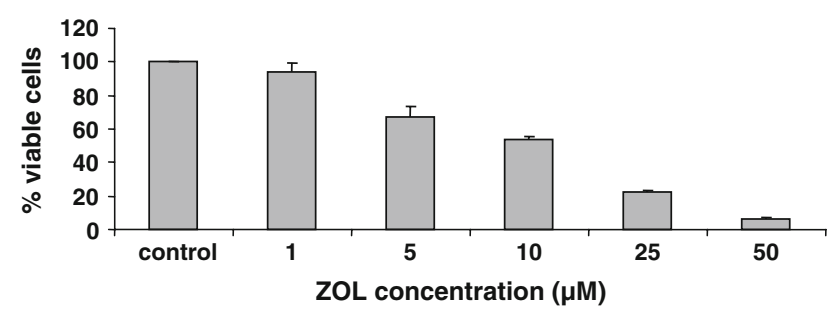

Fig. 1 Zoledronic acid inhibits growth of tumor cell lines of gastrointestinal heritage. HCT-116 were incubated with the indicated concentrations of ZOL. After 5 days of incubation cell count was determined by an MTT assay as described in methods. Shown is the average of three independent experiments concentration of ZOL affects the ability of HCT-116 cells to grow anchorage independently. We therefore subjected HCT-116 cells to a colony forming assay in a soft agar matrix with either $0,12.5$ or $25 \mu \mathrm{M}$ of ZOL in the agarmedium. Cells seeded into a soft agar layer on top of a bottom agar layer cannot attach to any surface and therefore have to grow anchorage independently, which is a hallmark of transformed and aggressively growing tumor cells [16]. After 14d in culture, cells in the control group formed a large number of colonies above the chosen cut-off size while cells treated with $25 \mu \mathrm{M}$ ZOL formed no visible colonies at all. The number of colonies in the $12.5 \mu \mathrm{M}$ group was significantly $(P<0.02)$ reduced as compared to untreated cells (Fig. 3). Also the size of the colonies in the $12.5 \mu \mathrm{M}$ ZOL group was visibly reduced as evidenced by the pictures included in Fig. 3. We next asked if the observed effect of ZOL on cell proliferation, cell cycle and colony formation was accompanied by an induction of apoptosis in the ZOL treated cells. To investigate if a population of cells undergoes apoptosis we screened whole protein extracts of ZOL treated HCT-116 for PARP cleavage products by western blot analysis. Cleavage of Poly-ADP-Ribose-Polymerase 1 (PARP) is an early and specific indicator of apoptotic programmed cell death [17]. PARP cleavage could be detected in protein extracts of HCT- 116 cells treated with 25 and $50 \mu \mathrm{M}$ of ZOL for $72 \mathrm{~h}$, indicating that the decrease of viable cells after $\mathrm{ZOL}$ treatment was either accompanied or partly due to an increase in tumor cell apoptosis (Fig. 4a). In order to assess the percentage of cells that undergo apoptosis, we treated cells with ZOL for $72 \mathrm{~h}$ and collected both adherent cells and cells from the cell culture supernatant. All cells were fixed and the percentage of apoptotic cells was determined by measuring the DNA content in a flow cytometer. The amount of cells with an apoptotic, sub G1-Phase DNA content increased from a basal $7 \%$ to more than $25 \%$ $(P<0.001)$ in the group treated with $50 \mu \mathrm{M}$ of $\mathrm{ZOL}$ (Fig. 4b). To further elucidate the mechanism of this observed induction of apoptosis we analyzed key apoptosis related proteins by western blot with special regard to caspase activation. To detect activated caspases, HCT-116 cells were incubated with $\mathrm{ZOL}$ concentrations ranging from 1 to $50 \mu \mathrm{M}$ for $72 \mathrm{~h}$ and whole cell protein extracts subjected to SDS-PAGE followed by western blotting and immunodetection of activated caspase cleavage products. ZOL treatment activated caspases 3 and 7, which are effector-caspases located at the end of the caspase cascade. Besides activation of caspases 3 and 7 we also detected cleavage of caspase 9 in ZOL treated HCT-116 cells, indicating an activation of the intrinsic, mitochondrial pathway of apoptosis induction. In addition we detected Caspase 8 cleavage products in the ZOL treated HCT-116 cells, further supporting an activation of the mitochondrial 
Fig. 2 Zoledronic acid induces a G1 cell cycle arrest. HCT-116 cells were incubated with the indicated concentrations of ZOL and DNA content was analyzed by flow cytometry. According to DNA content cells were allocated to the G1, S or G2 phases of the cell cycle. The figures on the left show the result of three independent experiments. The histograms on the right show an almost complete shift of the still adherent HCT-116 cells to the G1 peak of the cell cycle after treatment with $50 \mu \mathrm{M}$ ZOL for $72 \mathrm{~h}$

Fig. 3 Zoledronic acid inhibits anchorage independent growth of HCT-116. In each well 20,000 (60,000 for pictures) HCT-116 cells were seeded into a 3D agar matrix on top of a base agar layer in presence of 0 , 12.5 and $25 \mu \mathrm{M}$ of $\mathrm{ZOL}$ in both agar layers. After $14 \mathrm{~d}$ of incubation the number of colonies formed in each well was counted under a light microscope. The bars shown represent the average of three wells counted for each group. The results were confirmed in four independent experiments
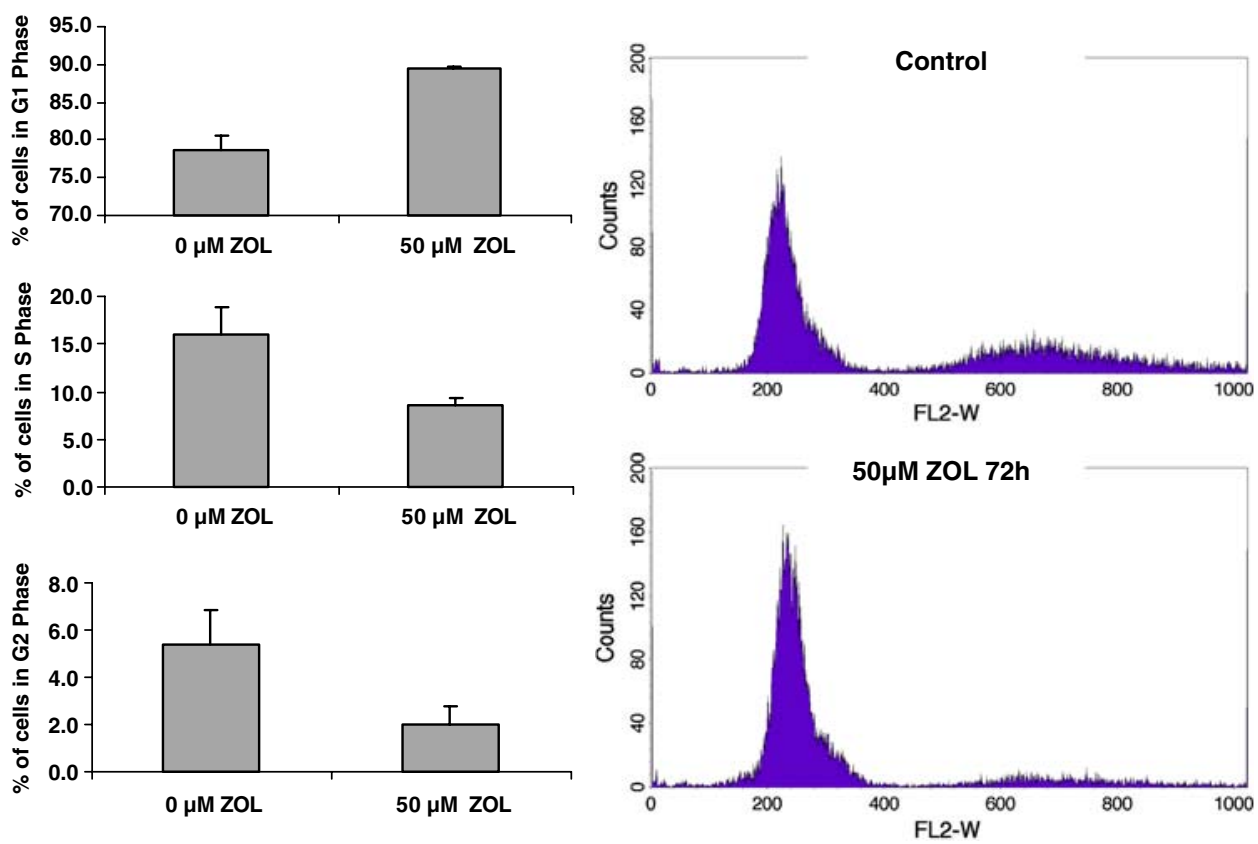

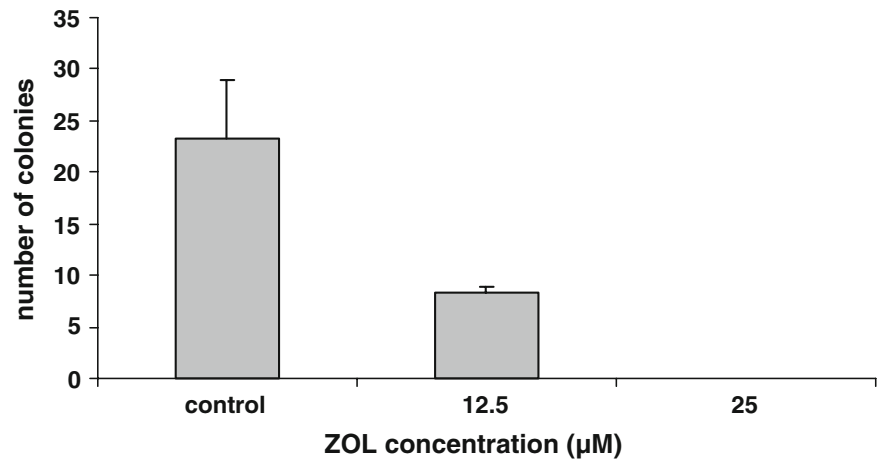

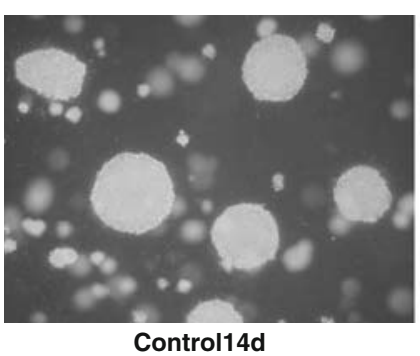

Control14d

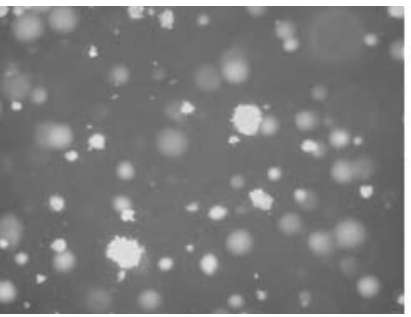

$12,5 \mu \mathrm{M} Z O \mathrm{~L}$ 14d

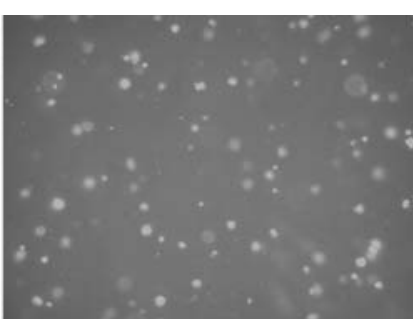

$25 \mu \mathrm{M}$ ZOL $14 \mathrm{~d}$ pathway. HCT-116 cells have been described as type II apoptotic cells $[18,19]$, where caspase 8 activation, together with activated caspase 9, initiates the mitochondrial apoptosis pathway. It should mentioned that only low concentrations of $5 \mu \mathrm{M}$ ZOL were sufficient to activate all the caspases mentioned above, with detectable caspase 7 activation occurring at only $1 \mu \mathrm{M}$ (Fig. 5). To substantiate an activation of the mitochondrial pathway of apoptosis, we next checked whether the observed activation of caspases was accompanied by a release of cytochrome $\mathrm{c}$ from the mitochondria into the cytosol. During the mitochondrial induction of apoptosis the mitochondrial membrane loses its membrane potential and becomes permeable, which results in a release of mitochondrial proteins into the cytosol [20]. We therefore prepared cytosolic protein extracts of HCT-116 cells treated with ZOL and analyzed cytochrome $\mathrm{c}$ levels by western blot detection. Compared to the untreated group, $72 \mathrm{~h}$ of $\mathrm{ZOL}$ treatment strongly increased the amount of cytochrome $\mathrm{c}$ in the cytosolic fraction of the treated cells, indicating a release from the apoptotic mitochondria into the cytosol (Fig. 6). If ZOL induces the mitochondrial pathway of apoptosis, there 

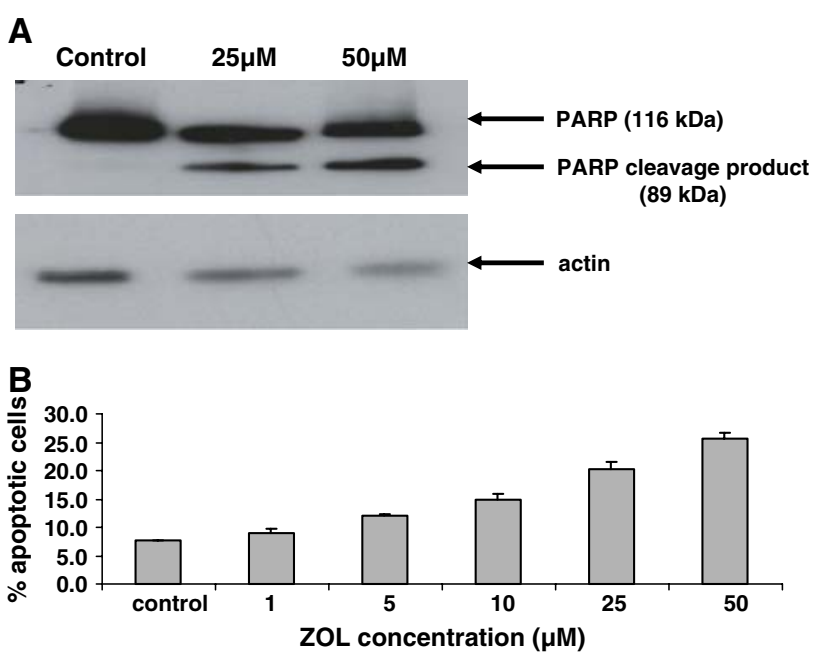

Fig. 4 Zoledronic acid induces apoptosis. (a) HCT-116 cells were incubated with ZOL for $72 \mathrm{~h}$ followed by western blot analysis of Poly-ADP-Ribose-Polymerase 1 (PARP) cleavage products. The amount of beta-actin protein served as loading control. (b) HCT116 cells were incubated with the indicated concentrations of ZOL and DNA content was analyzed by flow cytometry. Cells with a sub G1 Phase DNA content were counted as apoptotic cells. The bars represent one representative experiment in triplicates

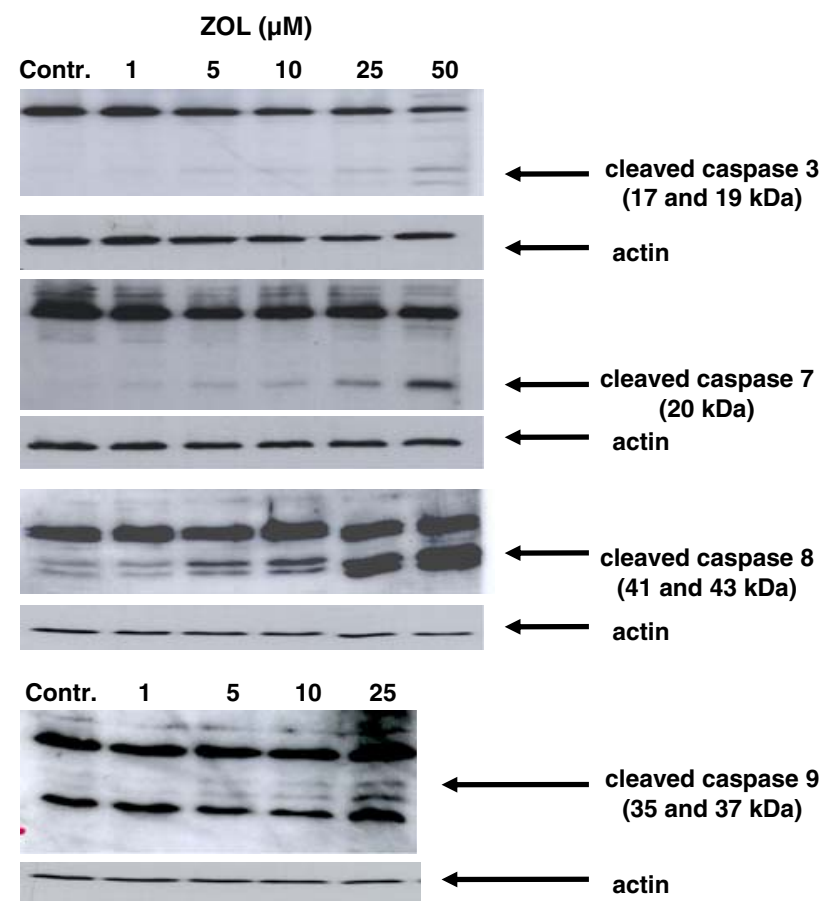

Fig. 5 Zoledronic acid induces activation of caspases 3, 7, 8 and 9 in HCT-116 cells. HCT-116 cells were incubated with ZOL for $72 \mathrm{~h}$ and whole protein extracts were subjected to western analysis of activated caspase cleavage products. Beta-actin $43 \mathrm{kDa}$ protein detection was used as control. All antibodies used detect full length procaspases as well as activated cleavage products. The bands above the caspase cleavage products are the uncleaved procaspases should be, together with the release of cytochrome $\mathrm{c}$ into the cytosol, a decrease of cytosolic Bax [20]. Bax is a proapoptotic member of the $\mathrm{Bcl}-2$ gene family which promotes apoptosis by translocation into the mitochondrial membrane and disruption of its integrity. Cytosolic protein extracts of ZOL treated cells were prepared and analyzed for their Bax level by western blotting. Indeed, treatment with $50 \mu \mathrm{M}$ ZOL for $72 \mathrm{~h}$ reduced the amount of Bax present in the cytosol. Since we observed a pronounced activation of caspase 8 , which is known to activate the proapoptotic Bcl-2 family member Bid by cleavage, we also analyzed the amount of full length Bid protein in whole cell extracts. While $25 \mu \mathrm{M}$ of $\mathrm{ZOL}$ somewhat reduced the amount of uncleaved Bid protein, $50 \mu \mathrm{M}$ of ZOL reduced the amount of full length Bid to almost undetectable levels (Fig. 6). In addition we analyzed the same whole cell extracts for the expression levels of the antiapoptotic Bcl-2 family members Bcl-2 and Bcl-xl. As expected Bcl-2 levels decreased substantially in the ZOL treated groups. In contrast, Bcl-xl levels were not affected (Fig. 6). Because previous studies have shown that ZOL treatment of tumor cells can cause a release of apoptosis inducing factor (AIF) from the mitochondria into the cytosol [21], we also analyzed AIF levels in our cytosolic protein extracts. As shown in Fig. 6, treatment of HCT-116 cells with ZOL for $72 \mathrm{~h}$ resulted in a release of AIF into the cytosol.

\section{Discussion}

ZOL, although not a classic cytostatic, had a pronounced cytotoxic effect on HCT-116 cells. Concentrations of $25 \mu \mathrm{M}$ and $50 \mu \mathrm{M}$ strongly inhibited cell proliferation and decreased the number of viable cells after 5 days of treatment by over $90 \%$. This dramatic reduction in tumor cell number can be caused by a slowing of cell proliferation as well as by an induction of apoptosis. Cell cycle analysis of the ZOL treated cells that had not yet detached from the cell culture surface revealed that a population of $\mathrm{ZOL}$ treated HCT-116 cells undergoes a G1 cell cycle arrest which suggests an impairment of cell cycle progression and a decrease of cell proliferation. ZOL acts as an inhibitor of the mevalonate pathway, ultimately preventing the prenylation of small GTPases such as Ras, Rho or Rac [3]. Inhibition of Ras mediated growth factor signalling can stall the progression through the cell cycle of a variety of tumor cell lines [22]. In agreement with this we found an inhibition of proliferation in ZOL treated HCT-116 cells. Since ZOL has been shown to decrease cell proliferation of lung cancer cells without any detectable induction of apoptosis [23], we needed to check if HCT-116 cells undergo apoptosis in addition to the slowing of cell proliferation. The 
Fig. 6 Zoledronic acid activates the mitochondrial pathway of apotosis in HCT116 cells. Cells were incubated with ZOL for $72 \mathrm{~h}$, followed by preparation of cytosolic protein extracts and western analysis of cytochrome C, Bax and AIF as indicated by the arrows. Whole cell extracts were used for the detection of Bid, Bcl-2 and Bcl$\mathrm{xl}$ proteins. $43 \mathrm{kDa}$ beta-actin was used as loading control for each sample
ZOL $(\mu \mathrm{M})$

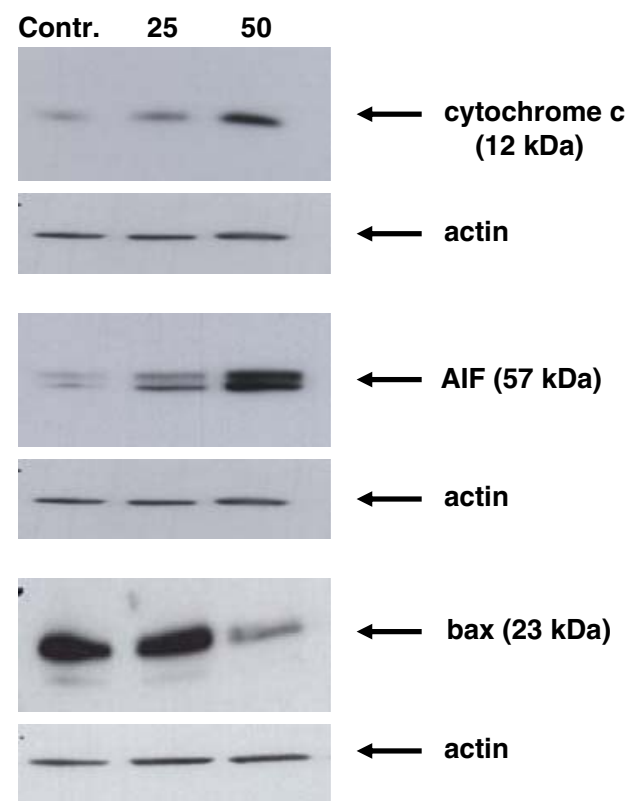

ZOL $(\mu \mathrm{M})$

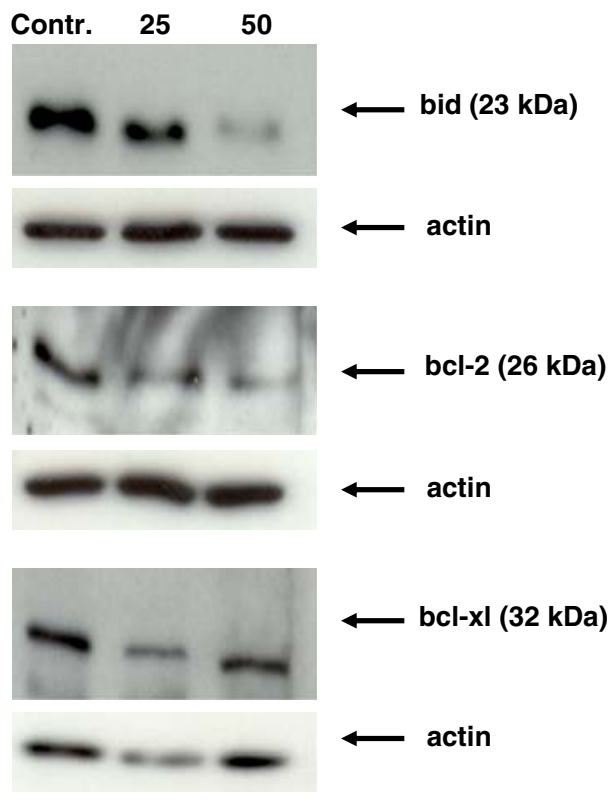

cleavage of PARP in ZOL treated HCT-116 cells clearly shows an induction of apoptosis. This was further confirmed by flow cytometric detection of apoptotic cells characterized by a sub G1 DNA content, which increased from $7 \%$ to $25 \%$. It is interesting to note that virtually all apoptotic cells had detached from the cell culture surface before undergoing apoptosis. The cell cycle analysis of the adherent cells revealed a G1 arrest but failed to detect any apoptotic cells. Only when the detached cells in the supernatant were harvested together with the adherent cells we detected a large percentage of apoptotic cells in the ZOL treated groups. This suggests that ZOL caused the detachment of HCT-116 cells with a subsequent induction of apoptosis. Since ZOL disrupts the prenylation of small GTPases, it is conceivable that an impaired function of Rho family GTPases caused the detachment of the HCT-116 cells via a disruption of cytoskeletal integrity. Indeed, ZOL has been shown to target the cytoskeleton of cells in a number of studies [24-26]. A recent study investigated the effect of a hexane extract from the plant Chios mastic gum on HCT-116 cells and observed a G1 arrest of the cells, followed by detachment and subsequent apoptosis [27]. Our data indicates that ZOL exerts a similar effect on HCT-116 cells.

Independent of the sequence of events we were able to show that ZOL induced apoptosis is caspase dependent, with detectable activation of caspases even at low concentrations of only 1-5 $\mu \mathrm{M}$ ZOL. Furthermore we were able to show that this induction of apoptosis includes the intrinsic, mitochondrial pathway, which is characterized by a translocation of Bax from the cytosol into the mitochondrial membrane thereby disrupting membrane integrity. Bax, a proapoptotic member of the Bcl-2 family exerts its effect by oligomerizing and thus contributing to permeabilisation of the mitochondrial outer membrane [28, 29]. This leads to a release of cytochrome $\mathrm{c}$ into the cytosol where it triggers a number of apoptotic events, including the activation of caspase 9 which in turn activates caspase 3 and caspase 7 [30]. In addition we observed a pronounced activation of the initiator caspase 8 starting at $5 \mu \mathrm{M}$ of ZOL. Although caspase 8 activation is generally associated with the death receptor mediated, extrinsic pathway of apoptosis its activation is commonly observed in cells treated with cytotoxic agents. Treatment of HCT-116 cells with the diterpene sclareol as well as exposure of HCT-116 cells to the cytotoxic agent WMC-79 resulted in an activation of the initiator caspase 8 together with caspase 9 $[31,32]$. In line with this result is the observed reduction of full length Bid protein in cell extracts from cells treated with 25 and $50 \mu \mathrm{M}$ ZOL. The proapoptotic Bcl-2 family protein Bid is cleaved and activated by caspase 8 and subsequently associates with proapoptotic Bax to disrupt mitochondrial integrity [33]. Together with this activation of Bid and Bax we found a decrease of overall Bcl-2 expression in whole cell extracts treated with 25 and $50 \mu \mathrm{M}$ of ZOL. This is in agreement with previous studies describing a downregulation of Bcl-2 in apoptotic HCT116 cells treated with cytotoxic agents [32]. Unexpectedly and in contrast to Bcl-2, Bcl-xl levels remained unaffected 
by treatment with ZOL. In spite of intact Bcl-xl levels our data suggests a ZOL induced activation of the mitochondrial pathway of apoptosis, including Caspase 8 mediated Bid activation, Bax translocation, cytochrome c release and finally an activation of the executioner caspases 3 and 7. In addition we detected an increase of AIF in the cytosolic fraction of ZOL treated HCT-116 cells, which is a key trigger of caspase independent apoptosis [34, 35]. It remains unclear whether ZOL causes apoptosis via a solely caspase dependent mechanism or if the AIF induced pathway is also involved. Our data shows that ZOL activates the intrinsic pathway of apoptosis induction via the mitochondrial pathway with a concurrent release of AIF into the cytosol. Because AIF is a key trigger of caspase independent apoptosis [35], we speculate that ZOL induces apoptotic cell death of HCT-116 cells in a caspase dependent and in a caspase independent mechanism. We furthermore demonstrated that HCT-116 cells treated with $25 \mu \mathrm{M}$ of ZOL completely lose their ability for anchorage independent growth in a soft agar matrix while $12.5 \mu \mathrm{M}$ severely reduce the number and size of the colonies. The ability to grow in soft agar is an indicator for the invasive potential of a tumor cell line [16]. Aggressively metastasizing tumor cells can invade through basement membranes and grow in the absence of anchorage to their native matrix environment to finally establish tumors in other tissues. The pronounced effect of ZOL in the soft agar assay indicates an inhibition of the invasive potential of HCT-116 colon carcinoma cells. Taken together, our data shows that ZOL has potent cytotoxic activity on HCT116 colon carcinoma cells even at low micromolar concentrations. Whether these findings can be used for the treatment of primary colon carcinoma or visceral metastases will need to be further studied. The nitrogen containing bisphosphonate minodronate has been shown to inhibit the growth of subcutaneous melanoma xenografts almost completely and thus significantly prolonged survival of the xenografted mice [13]. This leaves room to speculate that the related compound ZOL could potentially have the same potent action on primary tumors. ZOL itself effectively prevented the formation of lung metastases in an in vivo model, where osteosarcoma cells were injected intravenously into mice. In that study ZOL completely prevented the formation of lung metastasis and prolonged overall survival of the mice [36]. Another interesting thought is that although ZOL itself is not administered orally other bisphosphonates are routinely prescribed in tablet form for the treatment of osteoporosis. Since all bisphosphonates have a very limited intestinal absorption rate of only 1 to maximally $10 \%$ [37], there is a large fraction of the drug present in the colon. Taking into account the potent antitumoral effect of ZOL on a colon carcinoma cell line one could speculate that other, orally administered bisphosphonates have a chemopreventive effect on the development of colon carcinomas.

\section{References}

1. Heymann D, Ory B, Gouin F, Green JR, Rédini F (2004) Bisphosphonates: new therapeutic agents for the treatment of bone tumors. Trends Mol Med 10:7. Review

2. Clézardin P, Fournier P, Boissier S, Peyruchaud O (2003) In vitro and in vivo antitumor effects of bisphosphonates. Curr Med Chem 10:173-180. Review

3. Goffinet M, Thoulouzan M, Pradines A et al (2006) Zoledronic acid treatment impairs protein geranyl-geranylation for biological effects in prostatic cells. BMC Cancer 6:60

4. Denoyelle C, Hong L, Vannier JP, Soria J, Soria C (2003) New insights into the actions of bisphosphonate zoledronic acid in breast cancer cells by dual RhoA-dependent and - independent effects. Br J Cancer 88(10):1631-1640

5. Fromigue O, Kheddoumi N, Body JJ (2003) Bisphosphonates antagonise bone growth factoŕs effects on human breast cancer cells survival. Br J Cancer 89(1):178-184

6. Sohara Y, Shimada H, Scadeng M et al (2003) Lytic bone lesions in human neuroblastoma xenograft involve osteoclast recruitment and are inhibited by bisphosphonate. Cancer Res 63(12):3026-3031

7. Yuasa T, Kimura S, Ashihara E, Habuchi T, Maekawa T (2007) Zoledronic acid - a multiplicity of anti-cancer action. Curr Med Chem 14(20):2126-2135

8. Green JR (2004) Bisphosphonates: Preclinical review. Oncologist 9(Suppl 4):3-13. Review

9. Boissier S, Ferreras M, Peyruchaud O et al (2000) Bisphosphonates inhibit prostate and breast carcinoma cell invasion, an early event in the formation of bone metastases. Cancer Res 60(11):2949-2954

10. Smith MR (2005) Zoledronic acid to prevent skeletal complications in cancer: corrobating the evidence. Cancer Treat Rev 31(Suppl 3):19-25

11. Cohen MH, Dagher M, Griebel DJ et al (2002) U.S. food and drug administration drug approval summaries: Imatinib Mesylate, Mesna tablets and Zoledronic Acid. Oncologist 7(5):393-400

12. Hiraga T, Williams PJ, Ueda A, Tamura D, Yoneda T (2004) Zoledronic acid inhibits visceral metastases in the 4T1/luc mouse breast cancer model. Clin Cancer Res 10(13):4559-4567

13. Yamagishi S, Abe R, Inagaki Y et al (2004) Minodronate, a newly developed nitrogen-containing bisphosphonate, suppresses melanoma growth and improves survival in nude mice by blocking vascular endothelial growth factor signalling. Am J Pathol 165(6): 1865-1874

14. Giraudo E, Inouer M, Hanahan D (2004) An amino-bisphosphonate targets MMP-9-expressing macrophages and angiogenesis to impair cervical carcinogenesis. J Clin Invest 114(5):623-633

15. Okuno K (2007) Surgical treatment for digestive cancer. Curr Issu Colon Cancer Dig Surg 24(2):108-114. Review

16. Reddig PJ, Juliano RL (2005) Clinging to life: cell to matrix adhesion and cell survival. Cancer Metastasis Rev 24(3):425439. Review

17. Soldani C, Scovassi AI (2002) Poly(ADP-ribose) polymerase-1 cleavage during apoptosis: an update. Apoptosis 7(4):321-328. Review

18. Erhart LM, Lankat-Buttgereit B, Schmidt H, Wenzel U, Daniel H, Göke R (2005) Flavone initiates a hierarchical activation of the caspase-cascade in colon cancer cells. Apoptosis 10(3):611-617

19. Ozoren N, El-Deiry WS (2002) Defining characteristics of Type I and II apoptotic cells in response to TRAIL. Neoplasia 4(6):551-557 
20. Er E, Oliver L, Cartron PF, Juin P, Manon S, Vallette FM (2006) Mitochondria as the target of the pro-apoptotic protein Bax. Biochim Biophys Acta 1757(9-10):1301-1311. Epub 2006 May 27. Review

21. Ory B, Blanchard F, Battaglia S, Gouin F, Rédini F, Heymann D (2007) Zoledronic acid activates the DNA S-phase checkpoint and induces osteosarcoma cell death characterized by apoptosisinducing factor and endonuclease- $G$ translocation independently of p53 and retinoblastoma status. Mol Pharmacol 71(1):333-343

22. Walker K, Olson MF (2005) Targeting Ras and Rho GTPases as opportunities for cancer therapeutics. Curr Opin Genet Dev 15(1):62-68. Review

23. Li YY, Chang JW, Chou WC, Liaw CC, Wang HM, Huang JS, Wang CH, Yeh KY (2008) Zoledronic acid is unable to induce apoptosis, but slows tumor growth and prolongs survival for nonsmall-cell lung cancers. Lung Cancer 59(2):180-191

24. Ho LH, Read SH, Dorstyn L, Lambrusco L, Kumar S (2008) Caspase-2 is required for cell death induced by cytoskeletal disruption. Oncogene [Epub ahead of print]

25. Hasmim M, Bieler G, Rüegg C (2007) Zoledronate inhibits endothelial cell adhesion, migration and survival through the suppression of multiple, prenylation-dependent signaling pathways. J Thromb Haemost 5(1):166-173

26. Denoyelle C, Hong L, Vannier JP, Soria J, Soria C (2003) New insights into the actions of bisphosphonate zoledronic acid in breast cancer cells by dual RhoA-dependent and -independent effects. Br J Cancer 88(10):1631-1640

27. Balan KV, Demetzos C, Prince J, Dimas K, Cladaras M, Han Z, Wyche JH, Pantazis P (2005) Induction of apoptosis in human colon cancer HCT116 cells treated with an extract of the plant product, Chios mastic gum. In vivo 19(1):93-102

28. Brenner C, Grimm S (2006) The permeability transition pore complex in cancer cell death. Oncogene 25(34):4744-4756. Review. Erratum in: Oncogene. 25(50):6678
29. Chen M, Guerrero AD, Huang L et al (2007) Caspase-9-induced mitochondrial disruption through cleavage of anti-apoptotic BCL-2 family members. J Biol Chem 282(46):33888-33895

30. Garrido C, Galluzzi L, Brunet M, Puig PE, Didelot C, Kroemer G (2006) Mechanisms of cytochrome c release from mitochondria. Cell Death Differ 13(9):1423-1433. Epub 2006 May 5. Review

31. Paradissis A, Hatziantoniou S, Georgopoulos A, Psarra AM, Dimas K, Demetzos C (2007) Liposomes modify the subcellular distribution of sclareol uptake by HCT-116 cancer cell lines. Biomed Pharmacother 61(2-3):120-124

32. Kosakowska-Cholody T, Cholody WM, Monks A, Woynarowska BA, Michejda CJ (2005) WMC-79, a potent agent against colon cancers, induces apoptosis through a p53-dependent pathway. Mol Cancer Ther 4(10):1617-1627

33. Fehlberg S, Gregel CM, Göke A, Göke R. Bisphenol A (2003) diglycidyl ether-induced apoptosis involves Bax/Bid-dependent mitochondrial release of apoptosis-inducing factor (AIF), cytochrome c and Smac/DIABLO. Br J Pharmacol 139(3):495-500

34. Krantic S, Mechawar N, Reix S, Quirion R (2007) Apoptosisinducing factor: a matter of neuron life and death. Prog Neurobiol 81(3):179-196

35. Modjtahedi N, Giordanetto F, Madeo F, Kroemer G (2006) Apoptosis-inducing factor: vital and lethal. Trends Cell Biol 16(5):264-272. Epub 2006 Apr 18. Review

36. Ory B, Heymann MF, Kamijo A, Gouin F, Heymann D, Redini F (2005) Zoledronic acid suppresses lung metastases and prolongs overall survival of osteosarcoma-bearing mice. Cancer 104(11):2522-2529

37. Ezra A, Golomb G (2000) Administration routes and delivery systems of bisphosphonates for the treatment of bone resorption. Adv Drug Deliv Rev 42(3):175-195. Review 